\title{
Isabelle et Charles Emmanuel de Charriere, Correspondances et textes inédits
}

Paola Perazzolo

\section{(2) OpenEdition}

1 Journals

\section{Edizione digitale}

URL: http://journals.openedition.org/studifrancesi/9235

DOI: $10.4000 /$ studifrancesi.9235

ISSN: 2421-5856

\section{Editore}

Rosenberg \& Sellier

\section{Edizione cartacea}

Data di pubblicazione: 1 juin 2008

Paginazione: 194

ISSN: 0039-2944

\section{Notizia bibliografica digitale}

Paola Perazzolo, «Isabelle et Charles Emmanuel de Charriere, Correspondances et textes inédits», Studi Francesi [Online], 154 (LII | I) | 2008, online dal 30 novembre 2015, consultato il 13 janvier 2021. URL: http://journals.openedition.org/studifrancesi/9235 ; DOI: https://doi.org/10.4000/studifrancesi.9235

Questo documento è stato generato automaticamente il 13 janvier 2021.

\section{(c) (i) (9)}

Studi Francesi è distribuita con Licenza Creative Commons Attribuzione - Non commerciale - Non opere derivate 4.0 Internazionale. 


\title{
Isabelle et Charles Emmanuel de Charriere, Correspondances et textes inédits
}

\author{
Paola Perazzolo
}

\section{NOTIZIA}

ISABELLE et CHARLES EMMANUEL DE CHARRIERE, Correspondances et textes inédits, a cura di Guillemette Samson e Jean-Daniel Candaux, Paris, Honoré Champion, 2006 («L’âge des Lumières», 34), pp. 417.

1 A circa vent'anni di distanza dall'importante pubblicazione delle Euvres Complètes di Isabelle de Charrière (1979-1984) è uscito questo ulteriore volume, che raggruppa un insieme eterogeneo di documenti. La prima sezione, dedicata alla produzione narrativa dell'autrice, presenta quattro testi, provenienti dalla collezione del defunto Paul Chaponnière e acquistati dalle biblioteche di Neuchâtel e Ginevra. I primi due, Il y avoit dans une Ville de la Grece e Comment exprimer ma pensée?, sono stati pubblicati per la prima volta negli Annales Benjamin Constant nel 2003. Probabilmente databili intorno al 1796 o negli anni successivi, questi frammenti riprendono temi cari all'autrice e a Benjamin Constant. In entrambi viene riaffermata l'importanza di una relatività e di un'originalità di pensiero e di giudizio tanto più necessaria in quegli anni difficili, mentre nel secondo si ritrova il tema del valore delle parole, della fatuità della comunicazione e dei rapporti interpersonali, l'interesse per la situazione di una «femme perdue» - che fa pensare alla situazione di Caliste nelle Lettres écrites de Lausanne o di Ellénore in Adolphe -, vari dettagli e circostanze che potrebbero evocare esperienze passate di Constant. Ciò induce gli editori ad ipotizzare che il testo possa essere il frutto di una collaborazione che resta tuttavia difficilmente databile considerato il raffreddamento dei rapporti tra i due corrispondenti nel 1796, data suggerita nel testo. Deux frères, probabilmente redatto alla fine del secolo ma rimasto allo stato di bozza e di difficile datazione, illustra uno dei temi più cari alla scrittrice, 
cioè l'importanza dell'educazione, mentre Des auteurs et des livres, anch'esso frammentario, esprime il pensiero dell'autrice a proposito del proliferare delle autobiografie, considerate come il «débordement d'un loquace égoïsme».

La seconda sezione comprende un insieme di lettere di Isabelle de Charrière ritrovate dopo la pubblicazione dei sei volumi di corrispondenza dell'edizione Oorschot, che resta comunque il testo di riferimento principale a cui spesso rimanda l'editrice G. Samson per una migliore e più completa comprensione di questi trentadue documenti, di cui diciannove inediti, scritti tra il 1762 e il 1803. Completa il volume la corrispondenza completa di Charles-Emmanuel de Charrière, composta da 171 lettere redatte tra il 1756 e il 1807 . Se le lettere scritte alla moglie erano già state pubblicate, vengono ora proposti altri scritti poco o affatto conosciuti, che permettono di meglio conoscere un uomo che si rivela diverso dalla figura di piccolo e triste gentiluomo di campagna che giudizi critici un po' frettolosi avevano spesso considerato come uno degli artefici dell'infelicità di una moglie senz'altro più brillante e talentuosa.

3 Frutto del lavoro e della cooperazione di alcuni dei più importanti studiosi di Mme de Charrière - studiosi che avevano anche in maggior parte contribuito all'edizione precedente, di cui mantengono i criteri -, questo volume si propone come l'ideale completamento delle Euvres Complètes, e contribuisce ad una migliore comprensione della vita a Colombier, residenza della coppia Charrière, così come dell'opera dell'autrice, opera a cui lei stessa fa allusione in alcune delle lettere rimaste finora inedite. Questa pubblicazione si rivela dunque utile ed importante per lo studio e l'approfondimento di una scrittrice che continua a destare interesse, come ben testimoniano non solo il numero costantemente in aumento di articoli e lavori a lei dedicati, ma anche le continue riedizioni delle opere e le nuove traduzioni. 